REVISTA DE DERECHO UNED, núm. 3, 2008

\title{
DERECHO Y CINE: EL RITO, O EL DERECHO Y EL JUEZ SEGÚN EL REALISMO JURÍDICO ESCANDINAVO ${ }^{1}$
}

\author{
Prof. Dr. Juan Antonio Gómez García \\ Departamento de Filosofía jurídica, \\ Facultad de Derecho, UNED
}

A Ingmar Bergman, In memoriam (14-julio-1917; 30-julio-2007). En homenaje a uno de los primeros cineastas que me mostraron que el cine es algo más.

Resumen: Los estudios de Derecho y Cine constituyen una línea de investigación interdisciplinar, muy en boga en la actualidad en los estudios jurídicos, que tematiza, de una manera integradora, diversos aspectos del Derecho y del conocimiento jurídico como fenómenos socio-culturales, en relación con el hecho cinematográfico. Desde esta perspectiva epistemológica, el trabajo analiza una de las películas más interesantes del célebre cineasta sueco Ingmar Bergman, $E l$ rito (Riten, 1968), explicitando sus tesis en torno a la naturaleza de lo jurídico y de la función jurisdiccional, e incidiendo en su estrecha filiación con la pujante corriente teórica del realismo jurídico escandinavo.

Palabras clave: Los estudios de Derecho y Cine-Ingmar Bergman, El rito (Riten, 1968)- Realismo jurídico escandinavo.

1 Este trabajo se enmarca en el Proyecto de Investigación titulado Derecho, Cine y Literatura, SEJ2005-05469, cuyo Investigador Principal es el profesor Benjamín Rivaya. 
Abstract: Studies Law and Film constitute a line of interdisciplinary research, much in vogue today in the legal studies, which thematizes, in a manner inclusive, various aspects of law and legal knowledge as a socio-cultural phenomena, in connection with the indeed cinema. From this epistemological perspective, the paper analyzes one of the most interesting films of the famous Swedish filmmaker Ingmar Bergman, The rite (Riten, 1968), explaining his thesis on the nature of the legal and judicial duties, and insisting on his close affiliation with the burgeoning current theoretical Scandinavian Legal Realism.

Sumario. 1. Presupuestos metodológicos: los estudios de Derecho y Cine. 2. Sobre el temperamento artístico de Ingmar Bergman. 3. Argumento y concepción narrativa de El rito. 4. Una obra menor en arte mayor. 5 . El juez versus los actores. 6 . El proceso judicial como teatro. 7. Sobre el realismo jurídico en general, y el escandinavo en particular. 8. El juez Ernst Abrahamsson: un juez realista. 9. Un proceso realista. 10. ¿Dónde quedan los valores? 11. Fin.

\section{PRESUPUESTOS METODOLÓGICOS: LOS ESTUDIOS DE DERECHO Y CINE}

No vamos a descubrir aquí la gran importancia histórica del cine en la actualidad. El fenómeno cinematográfico surge a finales del siglo XIX, marcando desde este momento histórico el modus essendi de la cultura contemporánea y participando, pues, de la complejidad de todo fenómeno característico de la misma. El cine constituye un poderoso medio de comunicación social por su formidable capacidad para transmitir eficazmente ideas y mensajes, e implantar modelos de comportamiento, susceptibles de llegar a numerosísimas personas en todo el mundo ${ }^{2}$; así como una industria económica de primer or$\operatorname{den}^{3}$ y un extraordinario medio estético que permite gran cantidad de

2 Así por ejemplo, de las enormes potencialidades comunicativas del cine tomaron conciencia inmediatamente los grandes regímenes totalitarios del siglo $\mathrm{xx}$, los cuales se preocuparon muchísimo por crear y desarrollar industrias cinematográficas fuertes para propiciar la propagación de sus idearios. Por otra parte, sin ir más lejos, la identidad cultural de los Estados Unidos de América se ha forjado, en gran medida, sobre su poderosa industria cinematográfica, y la propia Iglesia católica tampoco ha sido ajena a esta idea: la encíclica del papa Pío XI, Vigilanti Cura (1936), así lo atestigua.

${ }^{3}$ El negocio del cinematógrafo mueve una gran cantidad de recursos, hasta el punto de que es, tal vez, la industria del ocio que ha tenido mayor incidencia económica desde su fundación. 
posibilidades artísticas en su ejecución ${ }^{4}$, de manera que, como tal arte, es una fuente inagotable de placer y entretenimiento.

Que el cine sea una de las manifestaciones culturales más importantes del siglo xx y lo que llevamos del xxI, impone necesariamente su toma en consideración como objeto de estudio por parte del investigador en el ámbito de las ciencias humanas y sociales, desde su perspectiva científica propia; también, naturalmente, desde la perspectiva científico-jurídica. Desde estos presupuestos epistemológicos, las relaciones entre derecho y cine se concretan fundamentalmente en dos aspectos. Por una parte, en la contemplación del cine como objeto sobre el que se aplica el derecho, como fenómeno sociocultural susceptible de regulación jurídica por parte del derecho positivo - el llamado derecho cinematográfico-. En este sentido, el derecho regula todo aquello que tiene que ver con las condiciones jurídicas para realizar, exhibir y explotar una obra cinematográfica, con las implicaciones jurídicas de la autoría de una película, con la censura, etc.... Por otra parte, el cine constituye un medio a través del cual se considera el fenómeno jurídico en toda su extensión de una determinada manera, precisamente por la presencia permanente de lo jurídico en la vida humana y, por tanto, en las historias narradas en la inmensa mayoría de las películas. Se justifica, así, la exposición y el análisis del tratamiento que se ha dispensado en general al derecho como producto humano en el medio cinematográfico ${ }^{5}$.

En el presente trabajo importa, sobre todo, el segundo de los aspectos. Las consideraciones de tipo estético sobre las películas quedan relegadas al mero plano instrumental, en la medida en que contribuyen a una mejor inteligibilidad del contenido jurídico del objeto de interpretación. No obstante, no puede obviarse una toma de consideración permanente sobre otros aspectos, como por ejemplo la idoneidad y las capacidades del medio cinematográfico, tanto en su dimensión estética como en su condición de mass media, para la transmisión de ideas y mensajes significativos desde el punto de vista jurídico, la importancia que tiene el cine como medio de expresión en general y en relación con la temática jurídica en particular, etc...

${ }_{4}$ Recuérdese el famoso tópico, lanzado por Ricciotto Canudo en su Manifiesto de las Siete Artes, de que el cine es el Séptimo Arte, como compendio y culminación de todas las demás (Vid. ROMAGUERA I RAMIÓ, Joaquim, ALSINA THEVENET, Homero, Textos y Manifiestos del Cine, Cátedra, Madrid, 1989, págs. 15-18).

5 Empleo aquí el término derecho en el sentido más amplio y más abierto que quepa establecerse, con el propósito de que esta aproximación a lo jurídico resulte lo más integradora y abarcadora posible, para poder contemplar así las más diversas concepciones en torno al derecho. 
Ello nos permitirá ubicarnos con mayor precisión en el ámbito en que ha de desarrollarse nuestra actividad crítica.

Los llamados estudios de Derecho y Cine comenzaron a desarrollarse en el ámbito académico anglosajón (en especial, en los Estados Unidos de América) ${ }^{6}$ a finales de la década de los ochenta del siglo pasado. El presupuesto metodológico fundamental de este peculiar acercamiento a lo jurídico es la consideración del material cinematográfico en general, y de cada película en particular, como textos jurídicos. Es la condición significativa, la lingüisticidad propia de las películas, la que sustenta este método de análisis crítico, ya que éstas son manifestaciones de un lenguaje que constituye y preserva su significatividad por encima de cualquier circunstancia o momento concretos.

Ello no implica, sin embargo, condenar a este material a un estatismo significativo absoluto, sino que su potencialidad significativa se

${ }^{6}$ Alli ha surgido el Law and Film Movement (también llamado Law and Cinema Movement), en el contexto de los denominados Cultural Legal Studies. Autores como John Denvir (Legal Reelism. Movies and Legal Texts, University of Illinois Press, Urbana, 1996), Paul Bergman y Michael Asimow (Reel Justice. The Courtroom Goes to the Movies, Andrews and McMeel, Kansas City, 1996), Norman Rosenberg (»Hollywood on Trials: Courts and Films. 1930-1960», en Law and History Review, n. ${ }^{\circ} 12,1994$, págs. 341-367), etc..., constituyen buenos ejemplos. En el ámbito hispano-parlante se vienen desarrollando estudios de este tipo desde hace algún tiempo, en el marco académico de lo que Benjamín Rivaya y Pablo de Cima han denominado como sociología del derecho en el cine y como pedagogía del derecho (RIVAYA, Benjamín, CIMA, Pablo de, Derecho y Cine en 100 películas. Una guía básica, Tirant lo Blanch, Valencia, 2004, pág. 95). Resultado de ello es la contemplación en varios planes de estudio de diversas universidades españolas, de la asignatura Derecho y Cine, y la constante celebración de cursos y seminarios de distinta índole sobre esta temática durante los últimos años; la colección de monografías de la editorial Tirant lo Blanch, titulada Derecho y Cine, y dirigida por el profesor Javier de Lucas; la institucionalización de estos estudios en el proyecto de investigación en cuyo marco se ubica este artículo, y cuyos integrantes vienen realizando diversos trabajos desde hace algunos años; el foro de estudio y discusión constituido bajo el nombre Fundación Cine y Derecho en Internet (www.cineyderecho.org); y diversos trabajos esporádicos publicados por distintos autores, como por ejemplo: VV.AA., Abogados de cine. Leyes y juicios en la pantalla, Ilustre Colegio de Abogados, Castalia, Madrid, 1996; el número monográfico de la revista de cine Nosferatu, n. ${ }^{\circ}$ 32, enero 2000; SAN MIGUEL PÉREZ, Enrique, Historia, Derecho y Cine, Ed. Centro de Estudios Ramón Areces, Madrid, 2003; SOTO NIETO, Francisco, FERNÁNDEZ, Francisco Javier, Imágenes y Justicia. El Derecho a través del cine, La Ley, Madrid, 2004; ROMERO, Emilio G., Otros abogados $y$ otros juicios en el cine español, Laertes, Barcelona, 2006; RIVAYA GARCÍA, Benjamín, PRESNO LLINERA, Miguel Ángel, Una introducción cinematográfica al Derecho, Tirant lo Blanch, Valencia, 2006; y mis trabajos: Valores jurídicos y derechos humanos en el Cine y Derecho y Cine, ambos publicados en Madrid por la Universidad Nacional de Educación a Distancia, en 2002 y 2006 respectivamente. 
actualiza permanentemente en virtud de su interpretación, de su lexis particular por parte de su receptor, puesto que la necesidad de contemplación por parte de alguien que, de suyo (no hay película sin espectador que la visione), conlleva la proyección de un filme para completarse perfectamente como texto, impone la particularización significativa de su generalidad, de su, valga la expresión, objetividad. De ahí que la textualidad del cine sea compleja, pluridimensional y tenga muchas implicaciones $\mathrm{y}$, por lo tanto, que sea susceptible de múltiples posibilidades interpretativas y de dar lugar a multitud de interpretaciones particulares de muy diversa índole: sobre el cine puede ejercerse una lectura (o varias a la vez) histórica, filosófica, sociológica, política, estética, económica, ... y jurídica.

Así pues, partimos aquí de una consideración de las películas como textos, al entender que esta última categoría constituye una unidad hermenéutica con la amplitud suficiente como para vincular todos los ejercicios interpretativos a que da, o puede dar lugar, un filme, privilegiando en este caso su lexis jurídica (como textos jurídicos, pues). Desde la analogía película-texto nos ubicamos en un lugar común (tópos) lo suficientemente comprensivo como para ejercer una mediación que permita dar cuenta, abierta y unitariamente, de toda la riqueza hermenéutica del cine en relación con lo jurídico (y, por lo demás, con otras interpretaciones). Comprendemos, así, lo cinematográfico dentro de una tradición histórico-cultural en constante actualización, la cual actúa conformando, a su vez, esta misma tradición en sus interpretaciones concretas, posibilitándose su entendimiento en razón de su discurso propio (estético, político, sociológico, económico, etc...), sin que quepa otorgar mayor peso a ninguno de los discursos sobre los demás.

En el ámbito del presente trabajo, como se viene indicando, se va a conceder mayor importancia del discurso jurídico. En concreto, se pretende tematizar una determinada manera de entender lo jurídico que ha tenido una gran influencia en la mentalidad jurídica contemporánea (la concepción jurídica realista, en especial la del realismo jurídico escandinavo), a propósito de la película El rito (Riten, Ingmar Bergman, 1968), ya que, a mi juicio, constituye un ejemplo notable, además de no estudiado, para ilustrar el tema de las relaciones entre derecho y cine, y para ejercer el tipo de análisis aquí planteado. 


\section{SOBRE EL TEMPERAMENTO ARTÍSTICO DEL CINEASTA INGMAR BERGMAN}

El día 30 de julio de 2007 falleció, a la edad de ochenta y nueve años, Ingmar Bergman, uno de los más grandes cineastas de la historia y una de las personalidades más poderosas del panorama artístico del siglo XX. Fue autor de una amplia filmografía, prolífico director teatral, dramaturgo y escritor literario ${ }^{7}$. Sus películas constituyen, en general, una honda y sentida reflexión en torno al ser humano en todas sus dimensiones existenciales.

La obra de Bergman se sustenta sobre la tradición antropológica y cultural de la teología y la ética luteranas nórdicas más rigoristas. Responde a una línea teológico-filosófica que entronca directamente con el existencialismo de Soren Kierkegaard ${ }^{8}$, en la línea de artistas como August Strindberg y Henrik Ibsen. El anhelo incondicional de vivir desde la interioridad del yo, el acentuado sentimiento de culpabilidad existencial y las turbulentas crisis anímicas del individuo, expresados en ideas como la angustia, el riesgo, la desesperación, la soledad, el fracaso, el temor, etc..., la presencia constante de lo religioso en su obra desde un subjetivismo filosófico radical y desde una actitud de sinceridad absoluta (Kierkegaard); así como la contempla-

7 Recuérdense filmes tan significativos como Juegos de verano (Sommarlek, 1950), El séptimo sello (Det sjunde Inseglet, 1956), Fresas salvajes (Smultronstället, 1957), Persona (Persona-Manniskoätama, 1965), Secretos de un matrimonio (Scener ur ett äktenskap, 1972), Fanny y Alexander (Fanny och Alexander, 1981) y Saraband (Saraband, 2003), su última película y auténtico testamento fílmico que sintetiza prácticamente todas las constantes temáticas y estilísticas de su obra. La biografía del autor puede leerse en forma de memorias en su imprescindible libro autobiográfico, La linterna mágica (trad. de M. Torres y F. Uriz, Tusquets, Barcelona, 1988), y completarse en su posterior Imágenes (trad. de J. Uriz Torres y F.J. Uriz, Tusquets, Barcelona, 1992). Otros relatos biográficos, y su obra cinematográfica y literaria más o menos completa (dependiendo del año de su publicación) pueden encontrarse en: BJÖRKMAN, Stig, MANNS, Torsten, SIMA, Jonas, Conversaciones con Ingmar Bergman, trad. de J. Jordá, Anagrama, Barcelona, 1975; COMPANY, Juan Miguel, Ingmar Bergman, 3. ${ }^{a}$ ed., Cátedra, Madrid, 1999; KALIN, Jesse, The Films of Ingmar Bergman, Cambridge University Press, Cambridge, 2003; ZUBIAUR CARREÑO, Francisco Javier, Ingmar Bergman. Fuentes creadoras del cineasta sueco, Ediciones Internacionales Universitarias, Madrid, 2004; y STEENE, Birgitta, Ingmar Bergman: a reference guide, Amsterdam University Press, Amsterdam, 2005.

${ }_{8}$ Bergman confesó en alguna ocasión sentir especial predilección por la obra de otro gran existencialista, Miguel de Unamuno, cuya tesis en torno al sentimiento trágico de la vida y sus temas típicos, como el sentimiento de culpa, el problema de la salvación eterna, y los conflictos entre razón y fe, razón y voluntad, y entre ciencia y vida, han dejado una fuerte impronta en la filmografía del cineasta sueco (Vid. ZUBIAUR CARREÑO, Francisco Javier, op. cit., pág. 124). 
ción de las relaciones y los conflictos humanos desde el más profundo escepticismo, su perspectiva acentuadamente psicologista, su acusada concentración dramática y sus atmósferas angustiosas, desesperanzadas y cargadas de tensión, donde se elude cualquier clase de efectismo, con pocos personajes -en muchos casos, femeninos- que interiorizan intensamente los conflictos dramáticos (Strindberg, Ibsen), influyeron poderosamente en la formación de Bergman y constituyeron un punto de partida fundamental en sus planteamientos artísticos ${ }^{9}$.

Los personajes de sus películas se nos presentan de manera directa, descarnada, expuestos abiertamente a sus circunstancias vitales desde su particular y compleja condición humana. Se aventuran por tortuosos senderos vitales desde su profunda radicalidad existencial, y en virtud de su particular individualidad, se enfrentan a sí mismos (a sus prejuicios, a sus deseos, a su sentido de culpabilidad,... a su propia identidad) desde su soledad propia y su específica (in)capacidad de (in)comunicación -iqué enorme importancia tiene la palabra en el cine de Bergman!--, y se confrontan con su entorno (su pareja, su familia, su círculo social, etc...) desnudando su alma, descubriéndola en su más intensa intimidad, en una vía sin retorno que los conduce, dependiendo de los casos, a la locura, a la muerte, a un estado de gracia, a un instante metafísico o a una revelación mística que determinará para siempre sus vidas. La explicitación de esos estados espirituales es el origen de historias densas, extraordinariamente dramáticas, y a la vez hermosas e intensamente poéticas, como pocos cineastas han conseguido representar en una pantalla.

El estilo narrativo de Bergman es intencionadamente lento, articulado sobre escenas y un montaje milimétricamente estudiados con el fin de que los actores puedan explayarse en la transmisión de los estados anímicos de sus personajes, y sobre imágenes de una excepcional limpidez, casi única en el arte cinematográfico ${ }^{10}$.

\section{ARGUMENTO Y CONCEPCIÓN NARRATIVA DE EL RITO}

A tres actores nacionalizados suizos, famosos internacionalmente -Hans y Thea Winkelmann, y Sebastian Fischer-, miembros de

9 Desde el punto de vista cinematográfico, Bergman es continuador, tanto temática como estilísticamente, de la tradición de los grandes cineastas suecos del cine mudo y de principios del sonoro, como Mauritz Stiller, Victor Sjöström y Alf Sjöberg.

10 Análoga a la de Dreyer, Ozu o Tarkovski, por poner algunos ejemplos señeros. 
una pequeña compañía teatral conocida con el nombre de Les Riens, los han denunciado por obscenidad con motivo de un número teatral representado por ellos, llamado El rito. Son requeridos a varios interrogatorios por parte de un juez, Ernst Abrahamsson, encargado de instruir el proceso. Thea Winkelmann estuvo casada con otro miembro de la compañía. Este murió en una pelea con Sebastian y Thea se ha vuelto a casar con Hans. En la sala de interrogatorios el juez se encuentra primero con los tres, luego interroga sucesivamente a Sebastian, Hans y Thea. Entre estas escenas tienen lugar encuentros de dos en dos -Sebastian y Thea, el juez con su confesor (recreado por el propio Bergman, en el único papel que interpretó como actor para el cine), Thea y Hans Winkelman, y este último y Sebastian. La tensión crece progresivamente durante el proceso, profundizándose cada vez con más virulencia en los conflictos internos y externos de los personajes, en una lucha dialéctica sin cuartel. En la última escena, los tres actores representan el número denunciado ante el juez a modo de venganza ante sus presiones psicológicas. El juez muere de un ataque al corazón por la impresión que le produce la escenificación ${ }^{11}$.

La acción está organizada narrativamente en nueve actos, como si de una obra de teatro se tratara, donde el primero y el último funcionan a modo de prólogo y epílogo respectivamente, pues en ellos aparecen los cuatro personajes de la película, y constituyen su planteamiento y desenlace. Las siete escenas restantes son todas con sólo dos personajes. La estructura es la siguiente:

Escena Primera: Una sala de entrevistas en el juzgado. Juez, Hans, Thea y Sebastian.

Escena Segunda: Una habitación de hotel. Thea y Sebastian.

Escena Tercera: Una sala de entrevistas en el juzgado. Juez y Sebastian.

Escena Cuarta: Un confesionario. Juez y su sacerdote confesor.

Escena Quinta: Una sala de entrevistas en el juzgado. Juez y Hans.

11 La película se inscribe en un período de la filmografía de Bergman, entre finales de la década de los sesenta y principios de los ochenta, caracterizado en general por la presencia central de la violencia, del miedo y de la degradación física y psíquica en la vida de sus personajes protagonistas. Filmes como Persona (Persona-Manniskoätarna, 1965) -con el que guarda muchas concomitancias temáticas y estilísticas El rito-, La hora del lobo (Vargtimmen, 1967), La vergüenza (Skammen, 1968), Pasión (En passion, 1969), Cara a cara... al desnudo (Ansikte mot ansikte, 1975), El huevo de la serpiente (Ormens ägg/Das Schlangenei, 1976) y De la vida de las marionetas (Ur marionetternas liv/Aus dem Leben der Marionetten, 1979-1980) son ejemplos al respecto. 
Escena Sexta: Un camerino. Hans y Thea. Thea.

Escena Séptima: Una sala de entrevistas en el juzgado. Juez y

Escena Octava: Un bar. Hans y Sebastian.

Escena Nueve: Una sala de entrevistas en el juzgado. Juez, Hans, Thea y Sebastian.

\section{UNA OBRA MENOR EN ARTE MAYOR}

El rito es considerada comúnmente por la crítica como una obra menor dentro de la filmografía de Bergman. Fue la primera película rodada por él para la televisión, y forma parte de su etapa creadora más hermética, tortuosa e incomprendida. Por aquel entonces, el cineasta era director de la Compañía Nacional de Teatro de Suecia, y su trabajo era constantemente puesto en tela de juicio, y sometido a revisión y restricciones artísticas por parte de las autoridades culturales de su país.

La propia concepción escénica y visual de la película, minimalista y estéticamente austera, como si se tratase de una pequeña pieza de cámara intimista, radicaliza una tendencia en su cine ya presente en sus obras desde principios de la década de los sesenta -como por ejemplo Los comulgantes (Nattvardgästerna, 1962), El silencio (Tystnaden, 1962) y Persona (Persona-Manniskoätarna, 1965)_, donde la cercanía, casi física, a los personajes, filmados en primeros y primerísimos planos, por momentos atosigantes en su obsesión por su fisicidad y en su larga duración, la desnudez de la puesta en escena con unos decorados reducidos a la mínima expresión y una potente fotografía en blanco y negro que otorga aspereza a la película, han sido valoradas en general por la crítica que se ha ocupado de su obra, como una especie de desarrollo, más o menos rutinario, de sus constantes estilísticas. Sin embargo, se suele olvidar que es este registro en el que Bergman ha cimentado su enorme arte al constituir el medio estético más apropiado para representar los temas recurrentes de su cine. El rito es, pues, una obra que no debe soslayarse, desde el punto de vista estético, tan apresurada y frívolamente como a menudo se hace.

Asimismo, El rito es una de las películas de Bergman que trata de manera más directa, intensa y descarnada sobre las causas internas y externas de toda forma de conflicto entre los seres humanos, y lo 
hace con la peculiaridad de enmarcarlo en el ámbito de un proceso judicial, es decir, mediante la remisión a un referente externo a la intimidad de los personajes como es el derecho en su expresión procesal, la manifestación más típicamente conflictual de lo jurídico. Este es un caso excepcional en la filmografía del cineasta, quien tematiza generalmente estas cuestiones de manera más abstracta. En este sentido, la película constituye una explícita reflexión en torno al papel del derecho y de las instituciones jurídicas en relación con los individuos y, especialmente, con su dimensión creativa y artística.

\section{EL JUEZ VERSUS LOS ACTORES}

Los personajes bergmanianos se caracterizan, en general, por su cuasi-permanente situación de insatisfacción personal. Son individuos anímicamente aislados de manera forzosa, que se sienten solos y desesperados, y que llegan incluso a la violencia y a la agresión física y psíquica cuando tal situación de angustia es extrema. Desde este planteamiento básico, el cineasta suele enfrentar dialécticamente dos tipos de personajes: los sujetos fríos, impecablemente racionales y dogmáticos, frente a los personajes atormentados, torturados interiormente, apasionados, materialistas y extremadamente vitalistas. En el fondo, este planteamiento no es otra cosa que una transposición dramatúrgica de la vieja estructura filosófica, de profunda raíz platónica, agustiniana y, más modernamente, ockhamista, que articula todo el pensamiento luterano, y de cuya tradición forma parte la obra de Bergman.

En El rito este esquema se plantea de la siguiente manera: el juez se presenta inicialmente como un individuo frío, calculador, dogmático con respecto a su trabajo, ejemplo prototípico del jurista continental; como un funcionario que realiza su trabajo sin el menor apego a sus emociones, que pretende actuar como una suerte de bouche de la loi en el cumplimiento de su tarea. En el filme está visualmente presentado, en la primera secuencia, escudriñando detalladamente con una lupa los papeles del expediente judicial abierto contra la compañía de actores. A partir de ahí, comienza insolentando a los actores con el obsceno relato ante los tres del lado oscuro de su pasado, e indagando sin tapujos en su más profunda intimidad. Para imponerse, no duda en emplear toda clase de manipulaciones y coacciones psicológicas valiéndose de la posición de poder que le otorga su condición de juez: graba los interrogatorios con los actores en un magnetofón, se ofrece a un soborno para no interrogar al personaje más 
débil psíquicamente del grupo (la vulnerable Thea), la agrede físicamente e intenta violarla durante su interrogatorio provocándole una fuerte crisis nerviosa, etc...

Y es que, a medida que avanza el metraje, se nos va presentando al mismo tiempo al juez como un individuo acomplejado por sus carencias físicas (tiene una fuerte tendencia a la sudoración corporal y, por ello, desprende un fuerte hedor) y atormentado por el reciente fallecimiento de su padre ${ }^{12}$. De hecho, en un momento dado, el juez invoca reiteradamente su deber jurídico como juez para justificar lo que está haciendo, dando muestras así de su carácter en el fondo inseguro y vulnerable, de su condición de víctima también de la situación forzada por el derecho en el presente proceso.

Los actores simbolizan el otro polo de la oposición: son personajes eminentemente pasionales, dotados de una acentuada carnalidad, afirmadores de su personalidad creativa frente a cualquier pretensión de aniquilar su tormentosa impulsividad. Sebastian es un individuo temperamental e inseguro que ha llevado una vida desmesurada y licenciosa: fue condenado años atrás por un homicidio, se ha casado y divorciado varias ocasiones, no sabe cuántos hijos tiene, etc... Hans es el personaje más comedido de los tres, aunque se encuentra insatisfecho con su vida y con sus dos compañeros, si bien permanece junto a ellos por la inercia de su trabajo y por el cariño (más o menos compasivo) que siente hacia su esposa, hasta el punto de consentir expresamente su relación adúltera con Sebastian. Thea es una mujer psíquicamente desestructurada, extremadamente frágil, y por ello, incapaz de relacionarse de manera equilibrada con los demás. Necesita la protección permanente que le otorga su esposo Hans. Es un personaje muy erotizado y mantiene, como he dicho, una relación adúltera regular con Sebastian.

\section{EL PROCESO JUDICIAL COMO TEATRO}

La película tiene una estructura dramática circular. Tomando como referencia fundamental la fase de instrucción del proceso judicial, con el pretexto de la investigación jurídica de los hechos, el guión plantea, desde su misma concepción narrativa (las sucesivas entrevistas de los actores con el juez, de ellos entre sí y del juez con su

12 Vid. escena cuarta de la película, con su sacerdote confesor, donde el juez manifiesta su miedo a la soledad y el terror que le produce enfrentarse a sus circunstancias existenciales. 
confesor como medio de manifestación de sus psiques, emociones y sentimientos), un desarrollo que da comienzo con la situación de poder y humillación del juez hacia los actores (escena 1) y que concluye con esta misma situación, pero a la inversa (escena 9), de los actores hacia el juez. Esta evolución progresa desde el uso, por parte del juez, de sus armas jurídicas, entendidas éstas como armas eminentemente psicológicas, con el propósito de humillar a los actores, mientras éstos tratan de defenderse para conjurarse al final e imponerse mediante la representación de su arte.

Todo ello desde la consideración del derecho en su dimensión genuinamente conflictual y activa, representada por el proceso judicial, como algo de naturaleza análoga a una representación teatral; lo que permite articular todo este desarrollo narrativo y dramático es, según Bergman, la semejanza entre proceso judicial y teatro. Además, el cineasta se sirve del motivo de la máscara para acentuar esta analogía: en la escena primera nos presenta al juez como un personaje que actúa oculto tras la máscara de su condición jurídica de funcionario público, mientras que en la última escena son los actores quienes actúan ataviados con las máscaras de la representación teatral objeto del proceso judicial ${ }^{13}$.

De esta manera, Bergman ubica derecho y teatro en un mismo nivel discursivo; ambos responden a las mismas raíces antropológicas, en tanto que beben de idénticas fuentes humanas, las cuales, en la película, se nos presentan como algo de naturaleza profundamente psicológica. En el filme, el rito teatral se acaba imponiendo sobre el rito jurídico. Afirma el juez al final de la película, inmediatamente antes de la representación teatral de los actores: «Admito que hay cierta crueldad también en mi profesión. Reprimir, humillar, juzgar e investigar. La lujuria de la crueldad. ¿De qué otro modo iba a ser posible? Se lo pregunto a ustedes, artistas; ustedes lo saben". ¿Acaso no es esta, parece sugerir Bergman, la única manera realista de contemplar lo jurídico?

${ }^{13}$ El motivo de la máscara es muy recurrente en el cine de Bergman. Se trata de una resonancia psicoanalítica, la cual, bien como persona, en su significado latino (recuérdese el título de una de sus más importantes películas: Persona), como elemento psíquico para ocultar exteriormente la auténtica naturaleza emocional del individuo, bien físicamente, como careta que cubre el rostro de los personajes, suele poner de manifiesto la tensión en que viven los personajes, entre su verdadera intimidad anímica y la realidad que les circunda, siendo así un medio de que éstos se dotan para intentar resolver esta tensión. La máscara, como dice J.M. Company, es «... apariencia y refugio del sujeto» (COMPANY, Juan Miguel, «El rincón de las fresas», en Cahiers du Cinema España, n. ${ }^{\circ}$, septiembre 2007, pág. 100). 


\section{SOBRE EL REALISMO JURÍDICO EN GENERAL Y EL ESCANDINAVO EN PARTICULAR}

En el ámbito filosófico-jurídico, el realismo en general arranca de la crítica a la dogmática formalista formulada por parte del segundo Ihering, cuando éste postuló la necesidad de comprender la norma jurídica desde su efectiva validez fáctica más que desde su formulación abstracta, y de considerar la fuerza como el verdadero contenido del derecho ${ }^{14}$.

Estas ideas constituyeron el programa teórico fundamental de corrientes decididamente antiformalistas en Alemania, como la $J u$ risprudencia de intereses (Heck, Müller-Erzbach, Triepel, Klein, etc...), la Escuela del derecho libre (Bülow, Kantorowicz, Fuchs, etc...) y tendencias explícitamente sociologistas como la inaugurada por Ehrlich. La primera de ellas postuló la interpretación de la norma jurídica como una actividad eminentemente creativa ${ }^{15}$, mientras que la segunda vindicó ya abiertamente la función creadora del juez en su aplicación ${ }^{16}$; Ehrlich llegó más allá al afirmar que el derecho, como fenómeno eminentemente social por encima de todo, debía ser comprendido ya desde una nueva perspectiva: la sociológica ${ }^{17}$.

En Francia fue la obra de Gény y su escuela (Esmein, Saleilles, Charmont, etc...) la que se hizo eco de los postulados de Ihering al proponer la elaboración de una verdadera Jurisprudencia sociológica, de naturaleza antimetafísica y antiformalista ${ }^{18}$. Entre sus discípulos,

${ }^{14}$ Escribe Ihering: «El derecho no es una idea lógica, sino una idea de fuerza; he ahí por qué la justicia, que sostiene en una mano la balanza donde se pesa el derecho, sostiene en la otra la espada que sirve para hacerlo efectivo. La espada, sin la balanza, es la fuerza bruta, y la balanza sin la espada, es el derecho en su impotencia» (IHERING, Rudolf von, La lucha por el derecho, trad. de A. Posada, Civitas, Madrid, 1985, p. 60).

is Vid., por ejemplo: HECK, Philipp, El problema de la creación del Derecho, trad. de M. Atienza, Comares, Granada, 1999; y MÜLLER-ERZBACH, Rudolf von, Die Relativität der Begriffe und ihre Begrenzung durch den Zweck des Gesetzes: Zur Beleuchtung d. Begriffsjurisprudenz, Fischer, Jena, 1913.

16 Vid. BÜLOW, Oskar, Gesetz und Richteramt, Scientia, Aalen, 1972; KANTOROWICZ, Hermann, La definición de derecho, trad. de J.M. de la Vega, Revista de Occidente, Madrid, 1964; KANTOROWICZ, Hermann, Rechtswissensachft und Soziologie: Ausgewälte Schriften zur Wissenschaftlehre, C.F. Müller, Karlsruhe, 1962; y FUCHS, Ernst, Gesammelte Schriften über Freirecht und Rechtsreform, Scientia, Aalen, 1975.

17 Vid. EHRLICH, Eugen, Grundlegung der Soziologie des Rechts, Duncker \& Humblot, Berlin, 1967; y EHRLICH, Eugen, Escritos sobre Sociología y Jurisprudencia, trad. y estudios preliminares de J.A. Gómez García, J.L. Muñoz de Baena Simón y G. Robles Morchón, Marcial Pons, Madrid, 2005.

18 Vid. GÉNY, François, Método de interpretación y fuentes del derecho privado positivo, trad. de J.L. Monereo Pérez, Comares, Granada, 2000. 
Duguit se declaró ya expresamente realista ${ }^{19}$ y desarrolló una línea teórica basada en la consideración del derecho como un hecho social y en el destierro de todo concepto (señaladamente el de derecho subjetivo y el de sujeto de derecho) de toda especulación jurídica que se tuviese por científica.

Por otra parte, en el contexto filosófico del pragmatismo empirista anglosajón (James, Dewey, Holmes) surge, a principios del siglo XX, el llamado realismo jurídico norteamericano, tradicionalmente emparentado con el escandinavo. Según la famosa caracterización de uno de los principales integrantes de este movimiento, Karl Llewellyn ${ }^{20}$, este realismo significó una forma de tematizar las cuestiones básicas de la ciencia jurídica sustentada sobre una concepción del derecho y de la actividad judicial como algo en acción (en correspondencia con una idéntica concepción de lo social), en tanto ambos son instrumentos para la consecución de fines sociales, y no fines en sí mismos. Desde el punto de vista epistemológico, el realismo jurídico norteamericano parte de la distinción neta entre ser y deber ser, dando primacía a lo que es frente a lo que debe ser, puesto que un juicio deóntico comporta un elemento añadido por parte de su autor, que desvirtúa lo que realmente es, y por tanto puede tergiversar algo tan fundamental en la determinación de lo jurídico como los hechos. En este sentido, las reglas técnicas y los conceptos jurídicos tradicionales de la dogmática, presuntamente indubitados descriptores de la actividad judicial (la actividad auténticamente jurídica, en tanto que el derecho es acción), no pueden merecer más que desconfianza, pasando, pues, a ocupar un segundo plano en el ámbito de la decisión judicial. En consecuencia, según esta tendencia, el derecho debe valorarse en razón de sus efectos, y éstos deben ser la verdadera pauta para quien investigue lo jurídico por encima de cualquier otro criterio ${ }^{21}$.

19 Vid. DUGUIT, Leon, El pragmatismo jurídico: conferencias pronunciadas en la Universidad de Madrid, trad. de A. Lázaro Alvárez, Ed. Francisco Beltrán, Madrid, 1924 , págs. 99 y ss.

20 Cfr. LLEWELLYN, Karl L., "Some Realism About Realism: Responding to Dean Pound», en Harvard Law Review, 44, Jun. 1931, págs. 1222-1264.

21 La descripción anterior corresponde a la tendencia, dentro del realismo norteamericano, caracterizada bajo la etiqueta de escépticos sobre las reglas. Asimismo, hubo otra tendencia, bajo el nombre de escépticos de los hechos, que incidió en mayor medida en la problematicidad que supone la determinación de los hechos jurídicamente relevantes en la decisión judicial, por encima del alcance de las reglas, de cara a establecer la auténtica naturaleza jurídica de lo que acontece en los tribunales; para ambas tendencias, los auténticos escenarios del derecho (el autor de esta distinción es Jerome N. Frank; vid. su trabajo, Law and the Modern Mind, Doubleday, Garden City, New York, 1963). 
Este panorama tan superficialmente expuesto del antiformalismo jurídico concluye en el llamado realismo jurídico escandinavo, el que aquí más nos interesa a los efectos del presente trabajo. Esta es una tendencia iusfilosófica nacida en el seno del neoempirismo contemporáneo, en la línea de los postulados filosóficos del positivismo lógico del Círculo de Viena, y más en concreto de los de la Escuela de Uppsala, uno de cuyos fundadores, Axel Hägerström, le dio auténtica carta de naturaleza filosófica.

Siguiendo el famoso trabajo de Tarello, titulado Realismo giuridi$\mathrm{CO}^{22}$, el realismo jurídico escandinavo se caracteriza, en general, por los siguientes rasgos:

1. ${ }^{a}$ Como teoría sobre la definición del derecho, como ontología jurídica, entiende que éste se da específicamente en el ámbito psíquico de las creencias como una realidad mágica, pero no como una realidad distinta a las otras que también se dan en ese mismo ámbito: el derecho es porque se cree (sobre presupuestos de índole metafísica, mágica dirían los realistas) que es una realidad específica - Hägerström, Olivecrona-. Así se expresa este último: «...el derecho es un eslabón en la cadena de causa y efecto. Tiene por lo tanto un lugar entre los hechos del mundo y del espacio, pero entonces no puede pertenecer al mismo tiempo a otro mundo. El derecho no puede, por una parte, ser un hecho (como lo es indudablemente) con causas naturales y efectos naturales, $y$, por la otra, algo extraño al vínculo de causa y efecto. Sostener lo contrario es pura superstición. Ello significaría - si es que significa algo realmente- que el derecho está investido de un poder sobrenatural ${ }^{23}$. En términos parecidos se expresa la otra gran línea de pensamiento de esta escuela -Ross—: «EI derecho es un orden que es experimentado y vivido como socialmente obligatorio ${ }^{24}$.

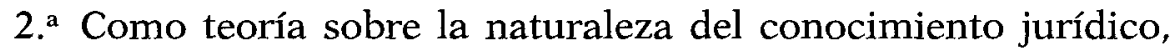
como epistemología jurídica, considera que su objeto de estudio son

22 Cfr. TARELLO, Giovanni, "Realismo giuridico», en AZARA, Antonio, EULA, Ernesto (dirs.), Novissimo Digesto Italiano, n. ${ }^{\circ}$ XIV, UTET, Torino, 1967, págs. 923 933.

23 OLIVECRONA, Karl, El Derecho como hecho, trad. de L. López Guerra, Labor, Barcelona, 1980, pág. 7. En referencia al lenguaje jurídico, afirma el autor: «El lenguaje jurídico tiene su origen en el lenguaje de la magia», y: "Hablamos [en referencia al lenguaje jurídico] como si creásemos efectos invisibles con simples palabras" (OLIVECRONA, Karl, Lenguaje jurídico y realidad, 3. ${ }^{\mathrm{a}}$ ed., trad. de E. Garzón Valdés, Fontamara, México, 1995, págs. 59 y 41 respectivamente).

${ }_{24}$ ROSS, Alf, Sobre el Derecho y la Justicia, trad. de G. Carrió, 2. ${ }^{\text {a }}$ ed., Eudeba, Buenos Aires, 1997, pág. 65. 
los hechos, afirmando que ese conocimiento, tal y como se ha venido dando hasta entonces, constituye una manipulación de lo real mediante el lenguaje y procedimientos rituales que se consideran como jurídicos, y como tales, sustentados en último término sobre creencias mágicas - Hägerström, Olivecrona, Lundstedt- ${ }^{25}$. Escribe Hägerström: «... debemos destruir la metafísica si queremos penetrar la bruma de las palabras, emanada de sentimientos y asociaciones, y pasar de los sonidos a las cosas»; y Olivecrona se reafirma en términos análogos cuando afirma: «Toda tentativa de sostener científicamente que el derecho es obligatorio en otro sentido que en el de ejercer una presión efectiva sobre la población, conduce necesariamente a absurdos y contradicciones. Aquí aparece, en consecuencia, la línea divisoria entre realismo y metafísica, entre el método científico y el misticismo en la explicación del derecho ${ }^{26}$. Asimismo, según Ross, es propio del conocimiento jurídico (como de las otras ciencias sociales: la sociología, la antropología, la psicología, etc...) la observación de la regularidad de determinadas conductas que son la base de la resolución de los conflictos jurídicos. Estas conductas fundan la validez de las normas jurídicas sobre las que se sustenta la resolución, porque (en consonancia con los presupuestos realistas expuestos en el punto anterior sobre cómo se concibe el derecho) son sentidas como obligatorias por parte de los jueces: «... un orden jurídico nacional -escribe Ross-, considerado como un sistema vigente de normas, puede ser definido como el conjunto de normas que efectivamente operan en el espíritu del juez, porque éste las vive como socialmente obligatorias y por eso las obedece» ${ }^{27}$.

3. a Como teoría sobre la interpretación y aplicación del derecho, el realismo jurídico escandinavo postula que estos procesos están mediados por un bagaje psíquico de raíz metafísica, mágica, intensamente tamizado por la ideología del intérprete (entendido éste y aquélla en el sentido en que lo hace la ciencia jurídica formalista: como mecánicos ejecutores de un silogismo lógico-deductivo), de modo que la individuación de los hechos y de las normas objeto de interpretación no está en absoluto predeterminada - Lundstedt ${ }^{28}$ -

25 Vid. HÄGERSTRÖM, Axel, Inquires into the Nature of Law and Morals, trad. de C.D. Broad, Almqvist \& Wiksells, Uppsala, 1953, pág. 354; OLIVECRONA, K., El Derecho como hecho, op.cit., passim; y LUNDSTEDT, A. Vilhelm, Legal Thinking Revised, Almqvist \& Wiksells, Uppsala, 1956, pág. 301.

26 HÄGERSTRÖM, Axel, «A Summary of my Philosophy», en Phylosophy and Religion, trad. de R.T. Sandin, George Allen \& Unwin Ltd., London, 1964, pág. 74; y OLIVECRONA, K., op.cit., pág. 7.

27 ROSS, A. op. cit., pág. 61.

28 Cfr. LUNDSTEDT, A. V., op. cit., págs. 131-136. 
En parecido sentido, Ross sostiene que las soluciones alcanzadas en la interpretación y aplicación del derecho son cuestiones exclusivamente fácticas, que dependen de las circunstancias concretas, y que no tienen porqué presentar una coincidencia necesaria con los enunciados jurídicos preexistentes, de tal modo que interpretación y aplicación han de ser tratados, pues, empíricamente, y no como procesos abstractos lógico-deductivos ${ }^{29}$.

A la caracterización precedente hay que añadir otro elemento, olvidado por Tarello y apuntado por Hierro ${ }^{30}$ : una concepción del derecho basada sobre la fuerza como contenido esencial de lo jurídico. Afirma Ross: «El derecho está constituido por reglas que están respaldadas por la fuerza»; y, por su parte, escribe Olivecrona: «Si el derecho no es vinculante en el sentido tradicional, si es solamente una cuestión del efecto psicológico de algunos imperativos independientes, si en realidad no hay derechos y obligaciones, entonces lo que llamamos derecho debe esencialmente ser fuerza organizada" ${ }^{31}$.

\section{EL JUEZ ERNST ABRAHAMSSON: UN JUEZ REALISTA}

Como he indicado arriba, es la concepción jurídica característica del realismo jurídico escandinavo la que actúa como presupuesto y subyace al personaje del juez y a toda la concepción dramática del filme. Estamos, por encima de todo, ante una concepción de la actividad jurisdiccional, y más específicamente la judicial, como algo que se desarrolla fundamentalmente en acción. Para los realistas escandinavos, la tarea judicial es una cuestión eminentemente práctica, condicionada en gran medida por actos volitivos del juez, aun cuando, como indica Ross, intervengan prima facie también procesos cognitivos que predisponen su actividad decisoria.

En la película, esta actividad es presentada en su más radical expresión fáctica, como un hecho: el proceso a una compañía de actores. La determinación de los hechos que se contemplan en la instrucción del proceso, está tamizada por las estructuras psíquicas del juez y los encausados, y por sus reacciones ante la situación jurídicoprocesal que los ha puesto en contacto y ha desencadenado sus rela-

29 ROSS, A., op. cit., págs. 143 y sigs.

${ }^{30}$ HIERRO, Liborio L., El realismo jurídico escandinavo. Una teoría empirista del derecho, Fernando Torres editor, Valencia, 1981, pág. 68.

31 ROSS, A., op. cit., pág. 79; y OLIVECRONA, K., El Derecho como hecho, op . cit., pág. 123. 
ciones personales. Esto es lo que determina la evolución psíquica de los personajes a lo largo del metraje. De presentarnos al juez inicialmente en una clara posición de poder frente a los actores, derivada de su especial condición político-jurídica de funcionario, asistimos a través de un proceso dialéctico cargado de tensión e intensidad dramáticas, a un paulatino desarrollo psíquico de los personajes en el que las posiciones se terminan igualando hasta la victoria final de los encausados. $\mathrm{El}$-en terminología de Olivecrona- carácter directivo que caracteriza al lenguaje jurídico, en el sentido de que influye, y pretende influir, en las conductas de los individuos de una determinada manera y en una cierta dirección, se muestra palpablemente desde el principio al final del filme, mostrando al derecho como un poderoso medio de control y comunicación sociales.

Ello pudiera inducir a pensar, en la línea de la teoría jurídica marxista (Stucka, Pashukanis), que el personaje del juez está concebido como el implacable ejecutor de la fuerza institucionalizada en que, según estos autores, consiste el derecho burgués ${ }^{32}$, efectuado en el proceso, el lugar donde lo jurídico se expresa más genuinamente al ser el escenario típico de la lucha de intereses en la sociedad burguesa, y donde se muestra más claramente, por abstraerse de su raíz económica, como un elemento superestructural del sistema capitalista $^{33}$. No obstante, en mi opinión, no es el punto de vista marxista el que interesa preferentemente a Bergman, sino el psicologista propio del realismo escandinavo; el primero sirve para ilustrar formalmente la lucha psicológica, pero esta lucha responde sobre todo a otro motivo, a la propia condición psíquica de los personajes en cuestión, más que a una crítica política sobre el sistema jurídico burgués.

En consecuencia, la película es una crítica implacable a la concepción positivista, formalista del juez, como ejecutor mecánico de un proceso cognoscitivo lógico-deductivo, como fría, calculadora, aséptica y racional bouche de la loi. Es la propia naturaleza psíquica del juez, y su evolución a lo largo del filme, lo que determina el auténtico modus essendi de la función judicial, en plena sintonía con los postulados teóricos del realismo jurídico escandinavo.

${ }^{32}$ En la película no se localiza la trama en ningún lugar; tan sólo se alude a la nacionalidad de los encausados. Ello acentúa, por otra parte, el carácter ejemplar que pretende tener todo lo que la película muestra.

${ }^{33}$ Cfr. STUCKA, Pëtr Ivanovic, La función revolucionaria del Derecho y del Estado, 2. ${ }^{a}$ ed., trad. de J.R. Capella, Península, Barcelona, 1974, pág. 34; y PASHUKANIS, E.B., Teoría General del Derecho y marxismo, trad. de V. Zapatero, Labor, Barcelona, 1976. 


\section{UN PROCESO REALISTA}

Como se ha apuntado más arriba, la acción jurisdiccional se muestra como una representación análoga a una teatral. La película está estructurada como un proceso en nueve escenas con una progresión dramática muy concreta. En consecuencia, el proceso (en su fase de instrucción: lo que muestra la película) se presenta como algo que no está rígidamente reglado según las estrictas normas del derecho procesal ${ }^{34}$; es más, comparte con la representación del número teatral (El rito) su carácter pagano, ritual, mágico. Bergman sitúa en idéntico nivel discursivo el proceso y la representación, en una lucha dialéctica entre la magia artística y la magia jurídica. El derecho se nos muestra, pues, como algo derivado de una concepción mágica para la resolución de los conflictos, al modo en que era postulado por Hägerström, por ejemplo.

A medida que va transcurriendo la instrucción del proceso, como se ha dicho antes, el juez ve progresivamente trastocada su actitud por la vía de la confrontación con la actitud artística de los actores, de tal modo que su bagaje pasional se va revelando poco a poco hasta acabar desbordado por sus propios demonios interiores ante la imposibilidad de encontrar la explicación que persigue fuera del ámbito artístico, en una especie de canto al triunfo del arte sobre la abstracta y calculadora racionalidad jurídica expresada en su figura institucional y en las leyes que tiene que aplicar. $Y$ es que los actores aguantan la confrontación con el juez (el proceso judicial en definitiva) gracias a la fuerza de su arte, una instancia trascendente que los mantiene a pesar de su inseguridad (Sebastian), de su miedo a la soledad y a la frustración (Hans) y de su irracionalidad rayana en la demencia (Thea). Este arte termina por imponerse en la representación final, donde los tres actores actúan como una sola persona bajo la férula del poder cuasi-místico de la creación artística.

Arte y derecho son incompatibles, parece decirnos Bergman ${ }^{35}$; el operador jurídico, tal y como es concebido por la tradición jurídica positivista occidental, no es más que una ficción mistificadora de la

${ }^{34}$ Ciertamente, como indica L. Hierro, los sistemas jurídicos escandinavos tienen una naturaleza intermedia entre los sistemas continentales de derecho civil o romano y los sistemas anglosajones del common law. Se caracterizan por su escasa codificación normativa, su escaso formalismo y una situación de equilibrio entre el principio de creación legislativa y el de creación judicial del derecho (Cfr. HIERRO, L., op. cit., págs. 128-129).

${ }_{35}$ Si hay un cineasta que ha vindicado la importancia vital del arte y de la expresión artística ha sido Bergman. En muchas de sus películas, la creación artística 
auténtica naturaleza del ser humano como instancia psíquica que se confronta permanentemente con la realidad que le rodea y que realiza juicios sobre ella, máxime en el caso del juez, el cual se encuentra además en la tesitura profesional de juzgar la bondad o maldad jurídica (moral en el fondo, según el cineasta) de la conducta de otros. De acuerdo con los presupuestos realistas del filme, Bergman considera al juez ante todo como, podríamos decir, un individuo de carne $y$ hueso, en consonancia con la propia naturaleza del derecho en tanto que algo no susceptible de ser encorsetado bajo la literalidad de los códigos y que, por su propia naturaleza problemática enraizada en la complejidad de la vida humana (en el sentido más amplio que quepa pensarse), desborda toda pretensión displicentemente formalizadora.

El arte, pues, como afirmación radical de la individualidad y de la libertad absoluta del sujeto, como instrumento de exorcización de los demonios personales y como vehículo político desenmascarador de falsas construcciones teóricas (en este caso, el derecho como orden racional y abstracto regulador de las conductas humanas y el juez racional como su aplicador prototípico) que no pretenden otra cosa que aniquilar la condición extremadamente vital del hombre contemporáneo.

La derrota física y psicológica del juez se produce en el marco del proceso jurídico, y no fuera de él. He aquí el gran mensaje (además el más profundamente jurídico) de la película, lo que pone de manifiesto, en definitiva, que el derecho es, ante todo, un fenómeno existencial, psicológico más (como el arte, el teatro, etc...), donde la forma en sí y la presunta justicia de su contenido quedan relegados a un segundo plano, en tanto que son las actitudes y conductas humanas derivadas de las normas lo que importa realmente al juez en su actividad decisoria. En palabras de Ross, «... el derecho consiste parcialmente en ser norma, pero no en el sentido tradicional de específicas significaciones o proposiciones sobre la validez normativa, sino exclusivamente como elemento integral del fenómeno jurídico, como hechos psicofísicos, expresiones que en parte reflejan y en parte crean a su vez reales actitudes de conducta. Las expresiones normativas vienen a consideración como eslabones en esta cadena de funciones y no, como lo supone el dogmatismo jurídico, como un sistema independiente de proposiciones normativas ${ }^{36}$.

aparece como un medio de redención personal, en virtud del cual el artista dota de sentido a su existencia.

36 ROSS, Alf, Hacia una ciencia realista del Derecho: crítica del dualismo en el Derecho, trad. de J. Barboza, Abeledo-Perrot, Buenos Aires, 1961, págs. 108-109. 


\section{0. ¿DÓNDE QUEDAN LOS VALORES?}

Desde un punto de vista axiológico, el filme responde a una concepción escéptica en torno a los valores, deudora de los planteamientos de la corriente realista escandinava: los juicios de valor que sustentan el derecho son expresión de los sentimientos y de los deseos de los individuos concretos que mantienen una relación jurídica; en el caso de la película, una relación jurídico-procesal. En consecuencia, los juicios de valor no son más que expresiones verbales, $\mathrm{y}$, por lo tanto, toda discusión en torno a los contenidos de los principios axiológicos resulta ser una mera elucubración sin fundamento racional y sin sentido. Creer en valores no es otra cosa, pues, que expresar emociones, que manifestar un placer o un disgusto por parte del individuo que valora; y proyectar esos sentimientos a la realidad en calidad de valores (morales, jurídicos, estéticos, etc...), supone incurrir en una suerte de fetichismo ${ }^{37}$, en el cual la construcción teórica en que consiste el valor, constituye el objeto de idolatría y veneración por parte de sus defensores, al atribuírsele poderes o cualidades sobrenaturales, lo que, en último término es expresión de una mentalidad primitiva.

Así pues, los juicios de valor no son en sí ni verdaderos ni falsos, al contrario que los juicios científicos, los cuales sí responden a esta condición. Se trata de una tesis que parte de una concepción empirista de la realidad, en el sentido de negar la existencia de cualquier realidad espiritual frente a la realidad empírica. No cabe, así, ninguna posibilidad de un conocimiento práctico, ni de especulación rigurosa, científica, en torno a la moral o a los valores jurídicos. Escribe Hägerström al respecto: «Una propiedad moral como tal —esto es, una proposición en el sentido de que una determinada acción representa un valor supremo- no puede ser calificada como verdadera o falsa. No hay en absoluto una proposición en el sentido de que la acción sea actual o verdaderamente la correcta ${ }^{38}$. Como sostiene Ross, toda re-

${ }^{37}$ Asimismo, el Estado no sería otra cosa que una especie de fetiche, un objeto de veneración irracional.

${ }^{38}$ HÄGERSTRÖM, Axel: Om moraliska föreställningars Sanning, Bonnier, Stockholm, 1911; cit. por HIERRO, L., op. cit., pág. 146. Esto no significa, como indica Ross, que deba desterrarse sin más la reflexión en torno a la moral y a los valores jurídicos, sino sólo en los términos que tradicionalmente se ha desarrollado desde la Grecia clásica hasta la contemporaneidad. Una correcta reflexión al respecto sería aquella que tratase los fenómenos morales como fenómenos psicofísicos en el contexto de un organismo psicofísico, de manera que entraría dentro del ámbito especulativo de las ciencias que se ocupan de estos fenómenos: la psicología y la sociología (Vid. ROSS, Alf, Kritik der sogenannten praktischen Erkenntnis. Zugleich Prolegomena zu einer Kritik der 
flexión filosófica sobre los valores es pura ideología, y como tal, un instrumento al servicio de intereses particulares dentro de la sociedad, de manera que la invocación de la justicia en relación con el derecho constituye un producto ideológico que se utiliza por una determinada causa interesada, sin que muestre el más mínimo criterio fundado en la realidad, el cual permita establecer, con certeza científica, si en verdad algo es justo o injusto. A lo sumo, sólo cabe hablar de un derecho justo cuando éste es realmente eficaz, es decir, aplicado, observado y cumplido en la vida social ${ }^{39}$.

Ciertamente, la película parte de estos presupuestos teóricos cuando presenta los valores como expresión de la individualidad particular (sobre todo, sentimental, emocional, irracional) de cada personaje, negando así la naturaleza cognoscitiva de los juicios morales; y cuando en ningún momento trae a colación valor o valores jurídicos algunos, que pudieran actuar como referentes axiológicos de los personajes durante el proceso judicial.

\section{FIN}

En consecuencia, de acuerdo con la concepción jurídica del realismo jurídico escandinavo, el derecho constituye una determinada experiencia de lo real en relación con las conductas humanas, que se manifiesta en su cumplimiento efectivo en la sociedad, y que se encuentra sometido, pues, al mismo bagaje antropológico y psíquico que cualquier otro fenómeno humano. Este es el auténtico presupuesto jurídico de la película; el pretexto iusfilosófico que permite a Bergman desplegar su concepción del hombre, en su condición de artista, en relación con lo social y lo jurídico.

$\mathrm{Y}$ es que $E l$ rito es un curioso y aleccionador ejemplo de cine juridico; más en concreto, de cine procesal. La gran mayoría de las películas procesales vienen a postular la tesis de que el proceso judicial es un escenario de conflictos, emociones, sentimientos y miserias humanos, puesto que este es el pretexto dramático de que se sirven para plantear y contar sus historias. En último término, vienen a igualar derecho y teatralidad como distintos modos de re-presentación, de retóricas en torno a los asuntos humanos, ubicando ambos

Rechtswissenschaft, Levin \& Munksgaard-Felix Meiner, Kobenhavn-Leipzig, 1933, págs. 435 y sigs.).

39 Cfr. ROSS, Alf, "Nota al libro de Kelsen, ¿Qué es la justicia?», en ROSS, Alf, El concepto de validez y otros ensayos, 2. ${ }^{2}$ ed., Fontamara, México, 1993, pp. 33-46. 
discursos (el jurídico y el teatral) en el mismo espacio simbólico. En la película de Bergman, esta tesis viene expresada con gran coherencia, desde los presupuestos teóricos de una de las más pujantes tendencias del pensamiento jurídico contemporáneo: el llamado realismo juridico escandinavo.

\section{FICHA TÉCNICA COMPLETA:}

Título original: Riten.

Producción: Svenks Filmindustri, Sveriges TV, Persona Film y AB Cinematograph.

Productor: Lars-Owe Carlberg.

Dirección y guión: Ingmar Bergman.

Decorados: Lennart Blomqvist.

Fotografía: Sven Nykvist (Blanco y negro, $16 \mathrm{~mm}$.).

Montaje: Siv Kanalv Lundgren.

Sonido: Lennart Egholm.

Vestuario: Mago.

Estreno en televisión: 25 de marzo de 1969.

Duración: 72 minutos.

Intérpretes: Ingrid Thulin (Thea Winkelmann), Anders Ek (Sebastian Fischer), Gunnar Björnstrand (Hans Winkelmann), Erik Hell (juez Abrahamsson), Ingmar Bergman (confesor). 